\title{
Estudio de factores socioculturales relacionados con la donación voluntaria de sangre en las Américas
}

\author{
Marcela García Gutiérrez, ${ }^{1}$ Eugenia Sáenz de Tejada ${ }^{1}$ \\ y José Ramiro Cruz ${ }^{1}$
}

RESUMEN Objetivo. Obtener información de base sobre los conocimientos, actitudes y prácticas relacionados con la donación voluntaria de sangre, así como la capacidad instalada de los bancos de sangre para la atención de donantes.

Métodos. El estudio se realizó en 15 países de la Región: Argentina, Bolivia, Colombia, Costa Rica, Cuba, Ecuador, El Salvador, Guatemala, Jamaica, Nicaragua, Panamá, Paraguay, Perú, República Dominicana y Venezuela, con la cooperación técnica de la Organización Panamericana de la Salud, oficina regional de la Organización Mundial de la Salud. Se utilizó una metodología formativa cualitativa mediante entrevistas a donantes, público en general y personal de salud, así como observación directa, grupos focales, pruebas de conocimientos y revisión documental.

Resultados. Se identificaron el conocimiento de las personas sobre la donación, sus creencias, percepciones y actitudes, sus barreras y motivaciones, al igual que los medios más eficaces para transmitir el mensaje a favor de la donación voluntaria.

Conclusiones. Esta información servirá como base para diseñar una estrategia en los países encaminada a promover la captación y lealtad de los donantes voluntarios de sangre. Esta estrategia podrá ser el sustento para llevar a la práctica los cambios necesarios en la atención y motivar a los donantes a regresar con regularidad a donar sangre.

Palabras clave Bancos de sangre, donantes de sangre, Américas.

Las transfusiones de sangre y de sus componentes constituyen el tratamiento más utilizado para corregir las pérdidas de sangre agudas y las anemias crónicas. En todos los casos, la unidad de sangre donada por una persona - el donante- es la que hace posible la transfusión sanguínea. El do-

\footnotetext{
1 Organización Panamericana de la Salud, Laboratorio y Bancos de Sangre, Washington, D.C., EE.UU. Toda correspondencia debe dirigirse a Marcela García Gutiérrez a la siguiente dirección postal: 525 Twenty-third Street, N.W., Washington, DC 20037, EE.UU. Tel.: (202) 974-3085
}

nante es el primer eslabón que determina la eficiencia de este proceso, sujeto a controversias debido a los efectos adversos que pueden estar asociados con él, pero vital, ya que aún no ha podido ser reemplazado por ningún otro tipo de terapia. Con el fin de prevenir los riesgos asociados a la transfusión, se han tomado distintas medidas, entre ellas la aplicación de criterios para la selección de los donantes, la aplicación de pruebas de tamizaje y la inactivación de virus. La selección de la población de donantes es la medida que ha tenido mayor impacto sobre la seguri- dad de la sangre. Se ha demostrado que una alta población de donantes voluntarios está asociada con una baja tasa de transmisión de los agentes infecciosos que suelen vincularse con la transfusión (1-5).

A pesar de que la mayoría de los reglamentos nacionales citan y reconocen la importancia de la donación voluntaria de sangre, en América Latina hay tres tipos de donantes de sangre (6):

- Donantes intrafamiliares o de sangre de reposición, quienes representan la gran mayoría 
- Donantes remunerados, que son reconocidos en varios países

- Donantes voluntarios, que constituyen una pequeña fracción del total

La Organización Panamericana de la Salud (OPS) tiene entre sus metas específicas lograr un suministro de sangre con el menor riesgo posible. Ante la situación que caracteriza la donación de sangre en América Latina - basada primordialmente en la reposición-, la promoción de la donación voluntaria y repetida de sangre es una carencia cuya corrección es impostergable.

En la resolución CD4 R15/99, la OPS expresa la necesidad de fortalecer los bancos de sangre en la Región, abogando por "... que se promueva el desarrollo de los programas nacionales de sangre y servicios de transfusión, con base en la donación voluntaria, altruista y repetida de sangre, como uno de los indicadores del desarrollo humano de la población".

Como un primer paso para conocer la situación de la Región se diseñó un estudio que arrojara información acerca del nivel de conocimiento que sobre la sangre, la transfusión y la donación de sangre tienen los donantes, la población en general y el propio personal de salud que labora en los bancos de sangre; las actitudes y prácticas de estas personas, así como el trato y la relación entre el personal y el donante. Además, esta investigación debía permitir conocer la capacidad instalada de los bancos de sangre, su infraestructura, su equipo y los materiales utilizados en el proceso de obtener una donación.

Con la información obtenida se podrá diseñar una estrategia de comunicación social en cada uno de los países participantes y en el ámbito regional, a fin de promover la captación y lealtad de donantes de sangre voluntarios que no reciben remuneración. Esta estrategia también se podrá utilizar como sustento para implantar los cambios necesarios en aras de brindar una mejor atención a los donantes y alentarlos a regresar a donar sangre con regularidad. Por último, estos resultados servirán de referencia para medir el impacto de las intervenciones que se realicen.

CUADRO 1. Características del trabajo realizado

\begin{tabular}{lcc}
\hline \multicolumn{1}{c}{ País } & $\begin{array}{c}\text { Investigadores locales } \\
\text { capacitados }\end{array}$ & $\begin{array}{c}\text { Bancos de sangre } \\
\text { participantes }\end{array}$ \\
\hline Argentina & 4 & 2 \\
Bolivia & 6 & 3 \\
Colombia & 3 & 5 \\
Costa Rica & 7 & 3 \\
Cuba & 12 & 4 \\
Ecuador & 5 & 3 \\
El Salvador & 5 & 3 \\
Guatemala & 5 & 2 \\
Jamaica & 4 & 3 \\
Nicaragua & 5 & 4 \\
Panamá & 10 & 3 \\
Paraguay & 5 & 4 \\
Perú & 12 & 20 \\
República Dominicana & 5 & 3 \\
Venezuela & 4 & 4 \\
Total & 92 & 66 \\
\hline
\end{tabular}

\section{MATERIALES Y MÉTODOS}

Para realizar esta investigación se utilizó una metodología formativa cualitativa basada en los lineamientos establecidos en la Guía metodológica para investigación de aspectos socio-culturales relacionados con donación voluntaria de sangre (7), preparada por la OPS con este fin. La investigación fue conducida por equipos nacionales previamente capacitados. Como técnicas de investigación se utilizaron las siguientes herramientas: entrevista, observación directa, grupo focal, prueba de conocimientos y revisión documental. Se aplicaron instrumentos predefinidos, adaptados a las condiciones propias de los diferentes países y validados con poblaciones similares a las que fueron objeto de estudio.

En la investigación participaron 92 investigadores locales capacitados y 46 bancos de sangre de 15 países (cuadro 1) incorporados al Programa Regional de la OPS. En la selección de las unidades de muestreo o ubicación de la investigación en cada país se tomaron en cuenta uno o dos de los siguientes criterios: zona geográfica, tipo de servicio, representatividad poblacional y representatividad institucional. Partiendo de estos criterios, las investigaciones se realizaron en bancos de sangre de la Cruz Roja y de hospitales regionales,

\section{CUADRO 2. Segmentos de población} seleccionados

- Personas que nunca habían donado y no tenían la intención de donar

- Personas que nunca habían donado, pero sí tenían la intención de donar

- Donantes recientes (voluntarios no remunerados, de reposición, remunerados, dirigidos, autólogos)

- Personas que alguna vez habían donado

- Personal de salud del banco sangre

hospitales públicos, el seguro social, centros regionales y centros nacionales.

La muestra estuvo conformada por segmentos de la población que de una forma $u$ otra estaban relacionados con la donación de sangre y por otros que no estaban directamente relacionados con ella. En el cuadro 2 se describen los segmentos de la población seleccionados.

\section{RESULTADOS}

\section{Con respecto a la población}

Conocimientos. La población tiene conocimientos generales sobre la sangre y su transfusión y donación, pero tiene una comprensión relativamente limitada de aspectos específicos. La población conoce que la sangre se repone, 
las funciones de la sangre, su propio tipo de sangre, situaciones más comunes en que una transfusión es necesaria, algunos requisitos y limitaciones para donar sangre y la cantidad de sangre que se extrae. No sabe cómo se reproduce la sangre ni conoce la cantidad de sangre en el cuerpo humano, el proceso de transfusión, el uso de la sangre donada, la necesidad de sangre, dónde y con qué frecuencia se puede donar, las enfermedades transmisibles y los beneficios y riesgos de donar sangre.

Además, en algunos países aún persisten tabúes y mitos sobre la sangre y la donación de sangre que probablemente influyen negativamente en las prácticas de donación. Algunas son que el tipo de sangre determina el temperamento o que la sangre muestra diferencias que radican en su color, consistencia y en las enfermedades de cada persona, o que donar sangre engorda, da hambre, adelgaza, provoca infartos, cáncer, convulsiones u otras enfermedades.

Actitudes. La mayoría de las personas tienen una actitud positiva y piensan que donar sangre es útil para salvar una vida y algo necesario y saludable. Las personas con actitud negativa piensan que se puede adquirir alguna enfermedad o aumentar de peso, y les temen al dolor y a la debilidad como consecuencia de la donación. También piensan que con la sangre se lucra y que es difícil conseguir donantes. En general las personas donarían si lo necesitara un familiar o amigo en caso de urgencia o para su buen estado de salud. Muchos donantes perciben que están donando su sangre para reponer la sangre utilizada por sus familiares; existe poca conciencia de las necesidades permanentes de la comunidad.

Las personas que nunca han donado no lo han hecho por falta de oportunidad o por temor a la sangre, a las agujas, al contagio, a debilitarse, o porque creen que no están en condiciones de ser donantes o que no van a recuperar la sangre que donan. Otras no cumplen con los requisitos de peso y talla.

Con respecto a los bancos de sangre, la mayoría de la población tiene una opinión positiva acerca de ellos, aunque existe una minoría cuya opinión es desfavorable. La mayoría de las personas opinaron que los bancos de sangre ofrecen una buena atención, que cuentan con personal calificado, que usan material adecuado y que entregan los resultados de las pruebas. Quienes tuvieron una opinión negativa señalaron como elementos desfavorables el tiempo que toma la donación, la falta de capacitación del personal para la venopunción, la desorganización, el mal trato y limitaciones en infraestructura y equipos.

Prácticas. La mayor parte de las personas que han donado durante el último año observan ciertas prácticas de donación que son comunes a la mayoría. Han donado en bancos de sangre de hospitales públicos, del seguro social o de la Cruz Roja y ha variado el tiempo transcurrido entre una donación y otra.

La mayoría de los donantes dieron su sangre porque alguien se lo pidió y volvería a donar si alguien se lo pidiera. Los voluntarios lo harían para ayudar a cualquier persona que lo necesitara.

Información, educación y comunicación. En la actualidad, algunos bancos de sangre realizan actividades de promoción a favor de la donación de sangre. En términos generales, la población ha estado expuesta a mensajes sobre el tema en los diversos medios. No obstante, las personas recomiendan que en el futuro se eduque, informe y motive a la población para que done. Para llevarlo a cabo recomiendan tratar temas como los beneficios y riesgos de la donación, despejar los mitos y creencias, e informar sobre el proceso, la necesidad de sangre, la importancia de la donación y el uso de la sangre colectada.

Según la población, los mensajes deben ser transmitidos por personal capacitado de los ministerios de salud y la Cruz Roja, profesionales de la salud, otros profesionales, los propios donantes, líderes de opinión y personas que han sobrevivido gracias a una transfusión. Esto debe realizarse me- diante charlas, conferencias, televisión, radio e Internet, impresos o folletos, afiches, prensa, cartillas interactivas, letreros y revistas. También resaltaron la importancia de los mecanismos interpersonales, como charlas, conferencias, cátedras, dramatizaciones y juegos para niños. Es importante utilizar todo el material educativo e informativo al alcance para la difusión en centros educativos, comunidades, lugares públicos como supermercados, tiendas, parques, servicios de salud, iglesias, lugares de trabajo y los hogares.

\section{Con respecto al personal de salud}

Conocimientos. En términos generales, el personal de salud de los bancos de sangre tiene el conocimiento técnico y la experiencia laboral requeridos para desempeñar sus actividades cotidianas. Sin embargo, es necesario reforzar determinados temas, especialmente el propio proceso de donación y la atención de los donantes, así como unificar criterios para orientar a los donantes sobre aspectos teóricos de la donación de sangre.

Actitud. En general el personal tiene el conocimiento técnico y la experiencia laboral, pero suele pensar que traer donantes es responsabilidad del paciente. La población dice donar por el deseo de salvar una vida, de ayudar, de hacer un bien, porque conoce la necesidad de sangre o, en ocasiones, por obligación hacia un familiar o compañero de trabajo. Considera que las personas no donan sangre porque tienen miedo a las agujas, a contagiarse, a tener resultados positivos a los marcadores con que se tamiza la sangre $o$, sencillamente, por falta de información.

Prácticas. En general el personal tiene el conocimiento técnico y la experiencia laboral, pero necesita conocer mejor las etapas del proceso de donación, pues muchas veces estas no tienen la calidad necesaria para garantizar la seguridad del donante y el receptor. Las tres etapas principales de la selección (asesoramiento y evaluación antes de 
la donación, historia clínica y control de salud) no se llevan a cabo de forma sistemática y completa. Además, el personal muchas veces no se muestra cordial con el donante, no lo saluda y no siempre es atento con él.

\section{Con respecto a los bancos de sangre}

Instalaciones. En general y con pocas excepciones, las instalaciones de los bancos de sangre no se encuentran en las mejores condiciones para el desarrollo de las actividades que desempeña el personal de salud ni para que el donante disfrute de la comodidad y seguridad requeridas durante la donación. Entre las limitaciones observadas se pueden citar:

- No existe un área específica para la ejecución de cada procedimiento.

- La ventilación, iluminación y limpieza no son adecuadas en algunos locales.

- Algunas áreas no tienen el tamaño ni la privacidad debidas.

- No hay instalaciones sanitarias para el uso del donante.

- El diseño y la decoración no son apropiados para la función.

- El mantenimiento deja mucho que desear.

- No hay servicios básicos, como teléfono, fax y transporte.

Equipos y suministros. Algunos bancos de sangre localizados en las ciudades principales disponen de los equipos y suministros necesarios para desarrollar sus actividades con la debida calidad. Por el contrario, hay otros que no cuentan con los elementos básicos indispensables para garantizar la seguridad de los procedimientos, como por ejemplo, equipos de primeros auxilios, balanzas, mezcladores, pesas, estetoscopios, tensiómetros, torniquetes, recipientes para desechos potencialmente infecciosos, recipientes para residuos no biológicos y suficientes sillas para los donantes.

Funcionamiento y servicio. Además de las limitaciones en infraestructura y equipamiento, existen otros problemas que influyen en que la atención que se le presta al donante no siempre sea la mejor. Hay limitaciones del número de empleados y personal de promoción. El horario de atención no es flexible, los registros no siempre son adecuados, no se les da importancia a las relaciones públicas ni al servicio del público. El proceso es lento. Existen problemas con el asesoramiento y orientación del donante, la entrevista no es sistemática, no hay un cuestionario estándar, el control y las recomendaciones no son regulares, no hay información actualizada sobre la donación, una vez extraída la sangre no se le ofrece un refrigerio al donante y no se realizan todas las pruebas recomendables a la sangre colectada.

Usuarios. Con la excepción de Cuba y algunos bancos de sangre en otros dos países de la Región, donde el porcentaje de donantes voluntarios es mayor, el resto de los bancos tienen un mayor número de donantes de reposición. Esto confirma que la donación por reposición es la práctica más común en la Región y, aunque no es la más recomendable, permite cumplir con la demanda de sangre cuando no se cuenta con suficientes donantes voluntarios no remunerados. Aunque la mayoría de los bancos de sangre no refieren tener donantes remunerados, la práctica parece ser bastante común en algunos países. Por lo general, estos donantes no admiten su condición directamente, se hacen pasar por familiares o amigos, por lo que no se detectan muy fácilmente y pasan por donantes de reposición.

\section{DISCUSIÓN}

A la luz de los resultados del estudio, a continuación se presenta una serie de recomendaciones que se espera puedan contribuir a la implementación de los cambios necesarios para brindar una mejor atención al donante y motivarlo a regresar regularmente, así como al diseño de una estrategia de comunicación social para promover la donación de sangre voluntaria. Las recomendaciones van dirigidas a tres sectores fundamentales: la población, el personal de salud y los bancos de sangre.

\section{La población}

Se puede evidenciar que el sistema de donación por reposición dificulta el establecimiento de un sistema de donación voluntaria. La mayor motivación expresada fue el hecho de que un familiar o un amigo necesitó sangre, lo que puede llevar a pensar que las personas podrían reservar su donación para estas situaciones especificas.

Es necesario diseñar una estrategia de comunicación social eficaz que contemple la información, educación y comunicación (IEC) y tome en consideración los temas que la población no conoce y los que desea conocer acerca de la sangre, las transfusiones, la donación; sus experiencias al respecto; su opinión sobre los bancos de sangre; su actitud hacia la donación; sus motivaciones para donar, así como las barreras que limitan la donación. Se deben tener en cuenta los medios, materiales, mensajes, puntos de distribución y fuentes de información que recomiendan. La estrategia de comunicación tendrá entonces que dirigirse a despertar la generosidad y solidaridad como principios básicos en la búsqueda de la seguridad transfusional.

La estrategia debe proyectar una perspectiva amplia, con la participación de varios sectores de la población. Los servicios de sangre no tienen la capacidad para adentrarse en los distintos estratos sociales y comunitarios para llevar la información a todos los ciudadanos y lograr su verdadero compromiso hacia la donación voluntaria de sangre. Para ello es necesario identificar las estructuras existentes en los países en aras de constituir alianzas estratégicas con la participación de distintos actores de los sectores de la salud, la educación y la comunicación.

Sin duda, los medios masivos de comunicación tienen un gran alcance, pero por su alto costo es necesario contemplar la utilización de otros medios de comunicación, así como la comunicación directa o personalizada.

Al igual que en otros campos donde se busca un cambio de actitud, es fundamental establecer programas de educación dirigidos a niños con miras a sensibilizarlos respecto de la donación de 
sangre. Estos programas deben ser llamativos para que despierten su interés.

\section{El personal de salud}

Preocupa el hecho de que el proceso de donación no se percibia como sistemático y seguro. Esta situación mina la confianza de la comunidad en el acto de donar su sangre. Por otro lado, la satisfacción del donante debe ser una preocupación constante de quienes le prestan el servicio e interactúan con él, por ser un factor determinante en lograr la "fidelidad" de las personas como donantes voluntarios de sangre. El objetivo de los bancos de sangre no es solo incorporar donantes voluntarios, sino lograr la donación repetida, ya que la sangre es más segura cuando proviene de personas mejor informadas y ha sido sometida a pruebas periódicas de laboratorio.

En consecuencia, es esencial adoptar estándares y requisitos nacionales mínimos en relación con la selección y atención de los donantes de sangre, tales como el registro antes de la donación, los criterios para la selección de los donantes y su evaluación, las pruebas de tamizaje para la investigación de agentes infecciosos asociados con la transfusión y las normas de bioseguridad. Los estándares de trabajo para bancos de sangre, publicados por la OPS constituyen una guía para el diseño de los estándares nacionales.

Se deben implementar programas eficientes de educación continua para instruir al personal sobre temas relacionados con la seguridad de la sangre y sus componentes, incluidas las diferentes etapas del proceso de donación. Adicionalmente, se debe insistir en la necesidad de capacitar a todo el personal que interactúa con los donantes acerca del servicio al público. Es preciso mejorar la atención y el trato brindados al donante.

El programa de educación a distancia es una buena alternativa. Su accesibilidad y el hecho de que los conocimientos que se adquieren se ponen en práctica en el lugar de trabajo permiten mejorar el servicio, y a la vez son fuentes de motivación para el personal, lo que mejorará su productividad y se reflejará en una mejor atención al donante.

Sin duda, oír la opinión del donante, conocer su grado de satisfacción y sus sugerencias puede beneficiar la prestación del servicio. Para ello son importantes las encuestas, los buzones de sugerencias, y otros medios.

De la misma forma como se han establecido foros de discusión e intercambio de ideas sobre algunos temas relacionados con los bancos de sangre y las entidades de medicina transfusional, vale la pena que esta experiencia se traslade a la promoción de la donación voluntaria haciendo partícipes a las personas que realizan directamente esa labor.

Por último es necesario que, mediante un trabajo sistemático de supervisión e inspección, se verifique que el personal cumpla con todas las especificaciones técnicas y las recomendaciones de calidad del servicio.

\section{Los bancos de sangre}

La promoción y el reclutamiento de donantes voluntarios es el primer eslabón de la cadena transfusional. Sin embargo, los resultados que se consigan estarán determinados por varios factores externos, como la accesibilidad del servicio y las condiciones bajo las cuales se realiza la donación.

Reconocer el valor de la promoción y de los donantes voluntarios de sangre dentro de la seguridad transfusional es el primer paso que se debe dar.

Tomando en cuenta la accesibilidad, la ubicación y el diseño de los hospitales en los países de nuestra Región, se recomienda que los bancos de sangre no estén dentro de las instalaciones hospitalarias. Sin embargo, la reorganización del sistema de bancos de sangre requiere voluntad política y exige una fuerte inversión económica. Esta decisión solo dependerá del grado de compromiso por parte de las autoridades nacionales con un suministro seguro y oportuno de sangre para su población.
Es de la mayor importancia mejorar la infraestructura, diseñar e instaurar un plan de mantenimiento y establecer las prioridades de cada banco de sangre. Se debe elaborar un inventario de los equipos y el mobiliario existentes, detallar el estado en que se encuentran, desarrollar un plan de equipamiento a corto, mediano y largo plazo, buscar fuentes de financiamiento y diseñar e implantar un plan de mantenimiento. Asimismo, es imprescindible contratar personal suficiente, especialmente personal que se haga cargo de la promoción de la donación voluntaria de sangre. Todo lo anterior es difícil de realizar debido al estado fragmentado del actual sistema. Por ello se insiste en la necesidad de concentrar estas actividades en pocos centros, sin sacrificar la oportunidad de que suministren sangre y sus componentes.

También es necesario analizar los pasos del proceso para reducir el tiempo que dura el procedimiento de la donación y mejorar el flujo que tienen los donantes durante su permanencia en los bancos de sangre. Otras medidas importantes pueden ser ampliar el horario de atención al donante para facilitar que las personas donen a su conveniencia y evitar aglomeraciones; motivar al donante de reposición e invitarlo a que vuelva a donar su sangre de manera voluntaria. Estas son tareas que pueden realizarse fácilmente en los bancos de sangre.

Dentro de la política y el plan nacional de sangre deben estar contempladas las estrategias para conseguir donantes voluntarios de sangre que sean fieles. Sería también conveniente que dentro del consejo nacional de sangre, uno de sus integrantes tenga la responsabilidad de promover la donación voluntaria de sangre.

Los esfuerzos que se realicen deben apuntar a atender las necesidades inmediatas de sangre y de sus componentes, pero no pueden descuidar el trabajo educativo con grupos jóvenes, porque en la medida en que se cuente con una población más educada se podrá lograr que la donación de sangre sea percibida como una responsabilidad social del ciudadano. 


\section{REFERENCIAS}

1. Dodd RY. Screening for hepatitis infectivity among blood donors: a model for blood safety. Arch Pathol Lab Med 1989;113:227-231.

2. Marin Lopez A. Prevalence of antibodies against human immunodeficiency virus (HIV) and other infectious disease markers in blood donors from the city of Puebla. Rev. Invest Clin 1987;39:219-222.

3. Nandi J, Bhawalkar V, Mody H, Elavia A, Desai PK, Banerjee K. Detection of HIV-1, HBV and $\mathrm{HCV}$ antibodies in blood donors from Surat, western India. Vox Sang 1994;67:406-407.

4. Mundee Y, Kamtorn N, Chaiyaphruk S, Nantachit N, Ness PM, Nelson KE. Infectious disease markers in blood donors in northern Thailand. Transfusion 1995;3:264-267.

5. Jager $H$, Nseka $K$, Goussard B, Kabeya CM, Rauhaus G, Peyerl G, Salaun JJ, Rehle T, Korte R. Voluntary blood donor recruitment: a strategy to reduce transmission of HIV-1, hepatitis$B$ and syphilis in Kinshasa, Zaire. Infusiontherapie 1990;17:224-226.

6. División de Desarrollo de Sistemas y Servicios de Salud. Medicina transfusional en América Latina 1994-2000. Washington D.C.: Organización Panamericana de la Salud; 2001. OPS/ HSE-LAB/04.2001. (Serie Medicamentos Esenciales y Tecnología).
7. División de Desarrollo de Sistemas y Servicios de Salud. Guía metodológica para investigación de aspectos socio-culturales relacionados con la donación voluntaria de sangre. Washington D.C.: Organización Panamericana de la Salud; 1999. (Serie Medicamentos Esenciales y Tecnología, No. 11)

Manuscrito recibido el 9 de septiembre de 2002. Aceptado para publicación, tras revisión, el 2 de enero de 2003.

ABSTRACT Objective. To obtain baseline data for countries of the Americas on knowledge, attitudes, and practices related to voluntary blood donation as well as on the current level and quality of services that blood banks provide to donors.

\section{A study of sociocultural factors related to voluntary blood donation in the Americas}

Methods. The study was conducted in 15 countries in the Americas: Argentina, Bolivia, Colombia, Costa Rica, Cuba, the Dominican Republic, Ecuador, El Salvador, Guatemala, Jamaica, Nicaragua, Panama, Paraguay, Peru, and Venezuela. Technical cooperation for the study came from the Pan American Health Organization. A qualitative formative methodology was applied, utilizing interviews with donors, health workers, and members of the general public; direct observation; focus groups; knowledge tests; and a review of documents.

Results. Information was generated on people's knowledge of donation; their beliefs, perceptions, attitudes, and motivations; and their barriers to donating. Knowledge was also gained as to the best means for disseminating messages supporting voluntary donation.

Conclusions. This information will serve as a foundation for designing a strategy in the countries of the Americas that is aimed at establishing and building the loyalty of voluntary blood donors. This strategy can support the implementation of changes needed in the care of donors, and it can also help in motivating donors to regularly return to donate blood. 